\title{
HYDRAULIC INVESTIGATIONS FOR THE ENVIRONMENTAL IMPACTS DUE TO TIDAL ENERGY DEVELOPMENT
}

\author{
Kyu-Han Kim, Catholic Kwandong University, khkim@cku.ac.kr \\ Bumshick Shin, Catholic Kwandong University, sbs114@cku.ac.kr \\ Jinsung Seo, Korea Environment Institute, popodong01@ kei.re.kr \\ Chong-Kun Pyun, Myongji Univ, ckpyun@mju.ac.kr
}

\begin{abstract}
INTRODUCTION
New ocean renewable energy has been developing around the world for a goal of reducing greenhouse gas emission. Tidal energy is more powerful and it has potential for future electricity generation among several ocean renewable energies even though not yet widely used. Also tides are more predictable than wind energy and solar energy.

SIHWA Lake Tidal Power Plant in South Korea is the largest tidal power installation in the world, with the total power output capacity of $254 \mathrm{MW}$. The project was opened in 2012 and a $12.5 \mathrm{~km}$ long seawall constructed in 1994 for flood mitigation and agricultural purpose. Power is generated on tidal inflows into the $30 \mathrm{~km}^{2}$ basin with the help of ten $25.4 \mathrm{MW}$ submerged bulb turbines. Eight culvert type sluice gates are used for the water outflow from the barrage. The amount of discharge flow in total ten of turbines is $3,000 \mathrm{~m} 3 / \mathrm{sec}$, and discharge flow in eight of water gate is $8,500 \mathrm{~m} 3 / \mathrm{sec}$.

At the time when SIHWA Lake Tidal Power Plant was designed for construction, its flow velocity was predicted as less than $2 \mathrm{~m} / \mathrm{sec}$ in front of water gate. Accordingly, discharge flow should have no significant impact on navigation channels and several berth facilities. It also should not affect on ship navigation.

However, within a year after the first run on April 2012, more than $2.5 \mathrm{~m} / \mathrm{sec}$ of flow velocity was generated and it damaged on navigation channels and berth facilities. Increased flow velocity at SIHWA sea area is directly impacting on ship navigation. In severe case, it will cause human and physical damages. In order to prevent these damages, it is necessary to find the causes and countermeasures of increased flow velocity for reduction in flow velocity of discharge.
\end{abstract}

\section{METHOD}

In this study, firstly, we established fine grid numerical simulation that can fully consider the physical conditions in the SIHWA sea area and the discharge characteristics. Secondly, we calculated current field to find causes of increase in flow velocity at SIHWA sea area in accordance with discharge conditions. Thirdly, we reproduced these complicated phenomenons and examined generated flow velocity through threedimensional hydraulic model test, and found countermeasures to reduce flow velocity. Lastly, we examined the stability of countermeasures simultaneously.

\section{RESULTS}

This study investigated intricate relationship between discharge flow, flow velocity and transition of current field from the operation of tidal power plant. The results can contribute to many sediment transport studies, as a basic data, on erosion and accretion phenomena due to strong flow velocity of discharge.

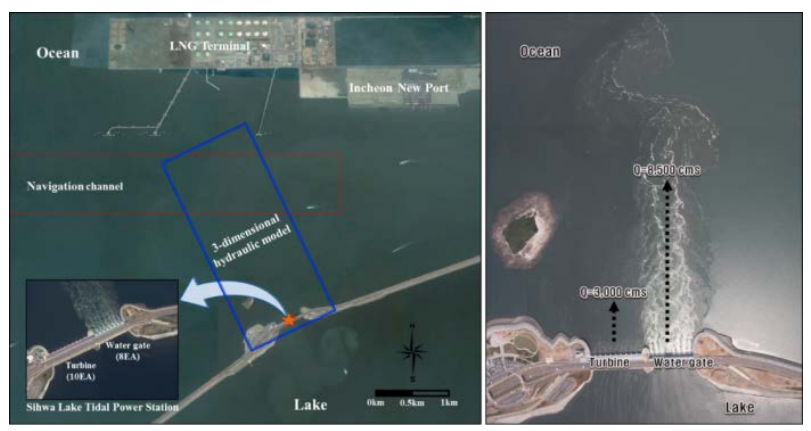

Figure 1 Location map of the study Area

(Left: location of tidal plant, Right: design discharge and jet current)
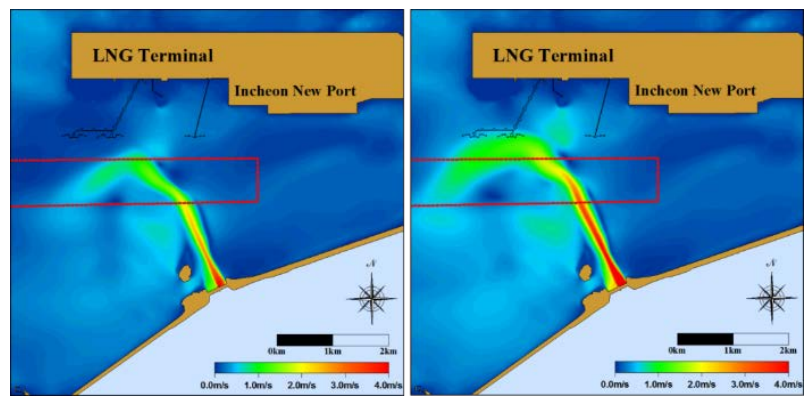

Figure 2 Numerical Simulation results

(Left: discharge $5,000 \mathrm{~m}^{3} / \mathrm{sec}$, Right: discharge 8,000 $\mathrm{m}^{3} / \mathrm{sec}$ )

\section{REFERENCES}

Hammons, T. J. (1993), Tidal power, Proceedings of the IEEE, 89(3), 419-433.

Frau JP.(1993), Tidal energy-promising projects: La Rance a successful industrial-scale experiment. IEEE Transactions on Energy Conversion, 8(3):552-8.

Jinsung Seo. (2016), A Numerical Study on the Coastal Hydraulic Affects, Ph.D. Dissertation, Catholic Kwandong University

Ikhyun Park. (2016), Numerical Investigation for the Hydraulic Environmental Changes on the Tidal Area, Master's Thesis(in Korean), Catholic Kwandong University 